\title{
A RESEARCH ON THE BREATHABILITY PROPERTY OF BABY DIAPER BACKSHEET
}

\author{
DOI: 10.35530/TT.2021.18
}

\author{
H.K. Kaynak, M. Alsayed* \\ Textile Engineering Department, Gaziantep University, Gaziantep, Turkey \\ (E-mail: tuluce@gantep.edu.tr, maheralsayyed99@gmail.com)
}

\begin{abstract}
Disposable breathable diapers are considered as one of the most important developments in diaper sector. Breathable diapers keep the child's skin dry and provide a comfortable feeling to the child. Breathability of diapers is obtained by using the breathable back sheet layer which is the most outer layer that the diaper comprises. In this study, the effects of laminating and printing processes on back sheet material breathability are studied. For this aim, four types of back sheet samples namely; film, printed film, laminated film and printedlaminated film are tested for breathability. For breathability testing, water vapour permeability test was applied with two different test devices which principally operate in different ambient conditions. As a result of the study, it is seen that, the breathability of back sheet component decreases as a result of printing and laminating processes. Also, it can be concluded that the ambient conditions for standard textile fabrics is not convenient for testing back sheet samples. Since, the test does not simulate the real ambient conditions of microclimate between the diaper and the child's skin during diaper use.
\end{abstract}

Keywords: back sheet, breathable diapers, breathability, water vapour permeability

\section{INTRODUCTION}

Baby diapers are used all over the world for many years. The crucial innovation in diapers is undoubtable the production of disposable diapers which are appeared in the middle of the twentieth century [1-3]. The disposable diapers are composed of different basic layers namely; top sheet, absorbent layer and back sheet. Each layer plays a different role, where the top sheet transports the liquid to the inner absorbent layer, while the absorbent layer is in charge of absorbing the liquid and the back sheet provides a liquid barrier effect [1-4].

In the literature there are some studies which deal with different performance properties of diapers. Yaman et al. investigated the surface, the mechanical and liquid absorption properties of commercial disposable diapers to determine their performance in use [4]. Özen et al. presented a study on the thermal comfort properties of multi-layered diaper structures regarding the breathability, thermal conductivity, and warmth-cool feeling in dry and wet conditions. They used different breathable films that were deliberately produced for the study in comparison to a commercial breathable film. They also used different top sheet layers [5]. Gündüz investigated the performance properties of commercially available baby diapers [6].

Baby's skin may be affected negatively by diapers. Since the skin is in contact with the diaper in wet and warm microclimate for a long time period [4]. To prevent the negative 
effects of diapers, breathable diapers are developed by providing a breathable back sheet layer which has a good level of water vapour permeability. Breathable diapers keep the child's skin dry and provide a comfortable feeling to the child. Earlier studies show that the breathable disposable diapers retain the skin in dry condition and inhibit the increase of heat, owing to having a good level of water vapour permeability. So, they are superior to non-breathable diapers regarding the comfort property. It can be said that the infants who wear breathable diapers are less likely to get rash than the ones who use the non-breathable diapers. One of the most effective solution for DD (Diaper dermatitis) or diaper rash is concluded as using breathable disposable diaper for infants [5, 7-12].

In order to produce a breathable disposable diaper, a breathable back sheet layer must be provided. Baby diapers can be called as breathable if only the back sheet layer provides breathability. Back sheet is composed of spun bonded nonwoven layer which is laminated with PE (polyethylene) film layer. It should be regarded that spun bonded nonwoven layer has water vapour permeability or breathability since it has a porous structure. On the other hand, it is fundamentally critical to present water vapour permeability for PE film layer which is originally used for liquid barrier functionality. Even if the PE film layer is originally breathable, there are some production processes such as printing that decrease the breathability of the component. The PE film layer is generally printed with different designs to provide an attractive look. The other deteriorative process for water vapour permeability is lamination of PE film with spun bonded nonwoven fabric by the adhesive material. Even though the spun bonded nonwoven fabric has breathability due to its porous structure, lamination of this textile layer by an adhesive with PE film deteriorates the breathability of end product.

In this study, the effects of printing and lamination processes on the breathability of baby diaper back sheet component were investigated by two different test devices which principally apply different ambient conditions.

\section{MATERIALS AND METHODS}

In this study, breathability of different configurations of diaper back sheet layers was investigated to discuss the effects of printing and lamination processes on water vapour permeability. For this aim, PE film, printed PE film, laminated PE film and laminated-printed PE film samples were tested. The mass and thickness values of the samples were determined according to the standards of TS 12127 [13] and TS 7128 EN ISO 5084 [14] and given in table 1.

Table 1. Fabric mass and thickness of the samples

\begin{tabular}{|c|c|c|}
\hline Samples & Fabric mass $\mathbf{( g / \mathbf { m } ^ { 2 } )}$ & Thickness (mm) \\
\hline PE film & 15 & 0.014 \\
\hline Laminated PE film & 25 & 0.024 \\
\hline Printed PE film & 15 & 0.128 \\
\hline Laminated \& Printed PE film & 26 & 0.116 \\
\hline
\end{tabular}

For breathability determination water vapour permeability tests were performed. In this study, two different types of water vapour permeability tests were applied to samples. The first test method is evaporative dish method by BS 7209:1990 [15] which is generally used for textile fabrics. In this method, three test specimens are mounted over the test dishes containing $46 \mathrm{ml}$ of distilled water at $20 \pm 2^{\circ} \mathrm{C}$. These dishes are placed on a rotating turntable. The samples are rotated with turntable for one hour to establish equilibrium of water vapour 
pressure gradient across the sample (figure 1).

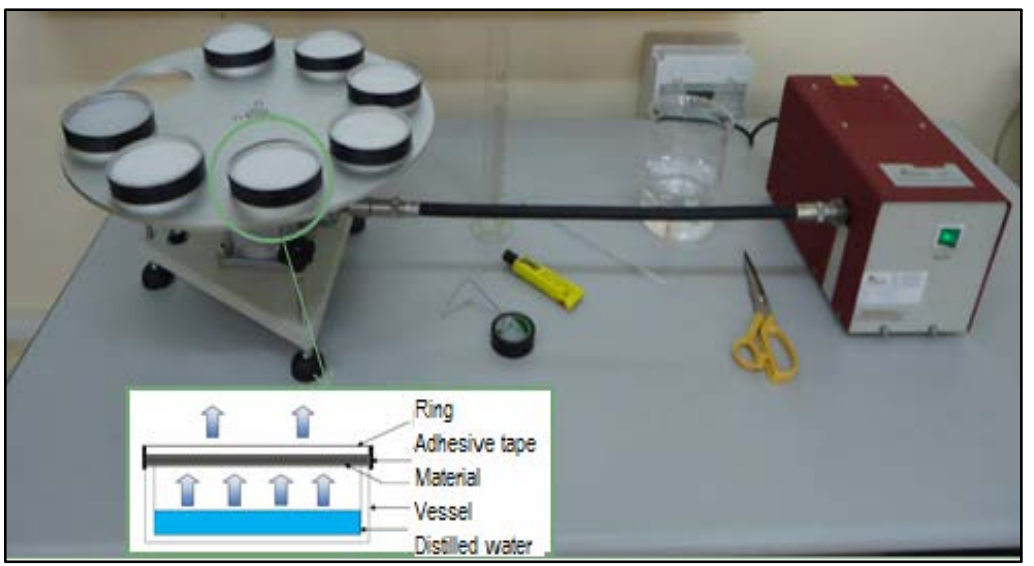

Figure 1. Water vapour permeability test device for evaporative dish method

After one hour rotating period for equilibrium the mass of the dishes are determined. The turntable with dishes is then rotated for a further period of 5 hours. The mass values of the dishes are determined after 5 hours duration. Then the water vapour permeability (WVP) of the samples is calculated in $\mathrm{g} / \mathrm{m}^{2} /$ day by the given equation 1 . The ambient conditions of the test are $20 \pm 2^{\circ} \mathrm{C}$ temperature and $65 \pm 4 \%$ relative humidity, as generally used for textile fabrics:

$$
\mathrm{WVP}=\frac{24 \mathrm{M}}{\mathrm{At}}
$$

where $t$ is test period in hours, $\mathrm{A}$ - area of the sample in $5.41 \times 10^{-3} \mathrm{~m}^{2}, \mathrm{M}$ - mass difference in grams.

The second type of breathability test was done by Mocon test device (figure 2) according to standard test method of ASTM D6701 - 21 [16], at $38^{\circ} \mathrm{C}$.

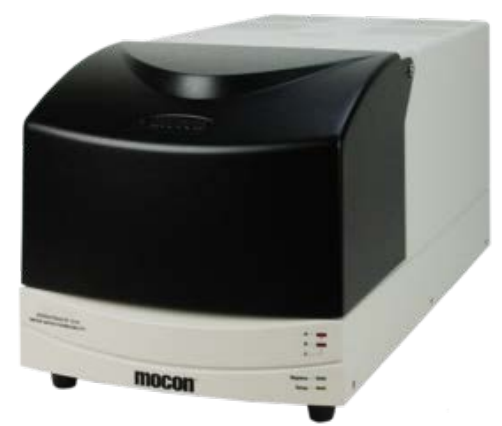

Figure 2. Mocon water vapour permeability test device

\section{RESULTS AND DISCUSSIONS}

Table 2 and figure 3 represents the experimental results of water vapour permeability test results determined by two different test principals. 
Table 2. The results of water vapour permeability tests

\begin{tabular}{|c|c|c|c|c|}
\hline \multirow{2}{*}{ Samples } & \multicolumn{2}{|c|}{ Evaporative Dish Method } & \multicolumn{2}{|c|}{ Breathability by Mocon } \\
\hline & WVP (g/m²/day) & Average & WVP $\left(\mathrm{g} / \mathrm{m}^{2} /\right.$ day $)$ & Average \\
\hline \multirow{5}{*}{ Film } & 557 & \multirow{5}{*}{457} & 4763 & \multirow{5}{*}{4400} \\
\hline & 448 & & 4339 & \\
\hline & 474 & & 4288 & \\
\hline & 420 & & 4248 & \\
\hline & 383 & & 4363 & \\
\hline \multirow{5}{*}{$\begin{array}{l}\text { Laminated } \\
\text { film }\end{array}$} & 511 & \multirow{5}{*}{466} & 3912 & \multirow{5}{*}{3711} \\
\hline & 471 & & 3872 & \\
\hline & 510 & & 3789 & \\
\hline & 426 & & 3416 & \\
\hline & 411 & & 3564 & \\
\hline \multirow{5}{*}{$\begin{array}{l}\text { Printed } \\
\text { film }\end{array}$} & 362 & \multirow{5}{*}{407} & 3418 & \multirow{5}{*}{3558} \\
\hline & 428 & & 3716 & \\
\hline & 440 & & 3571 & \\
\hline & 369 & & 3335 & \\
\hline & 437 & & 3750 & \\
\hline \multirow{5}{*}{$\begin{array}{l}\text { Printed } \\
\text { laminated } \\
\text { film }\end{array}$} & 413 & \multirow{5}{*}{466} & 2754 & \multirow{5}{*}{2522} \\
\hline & 573 & & 2582 & \\
\hline & 392 & & 2166 & \\
\hline & 424 & & 2335 & \\
\hline & 527 & & 2774 & \\
\hline
\end{tabular}

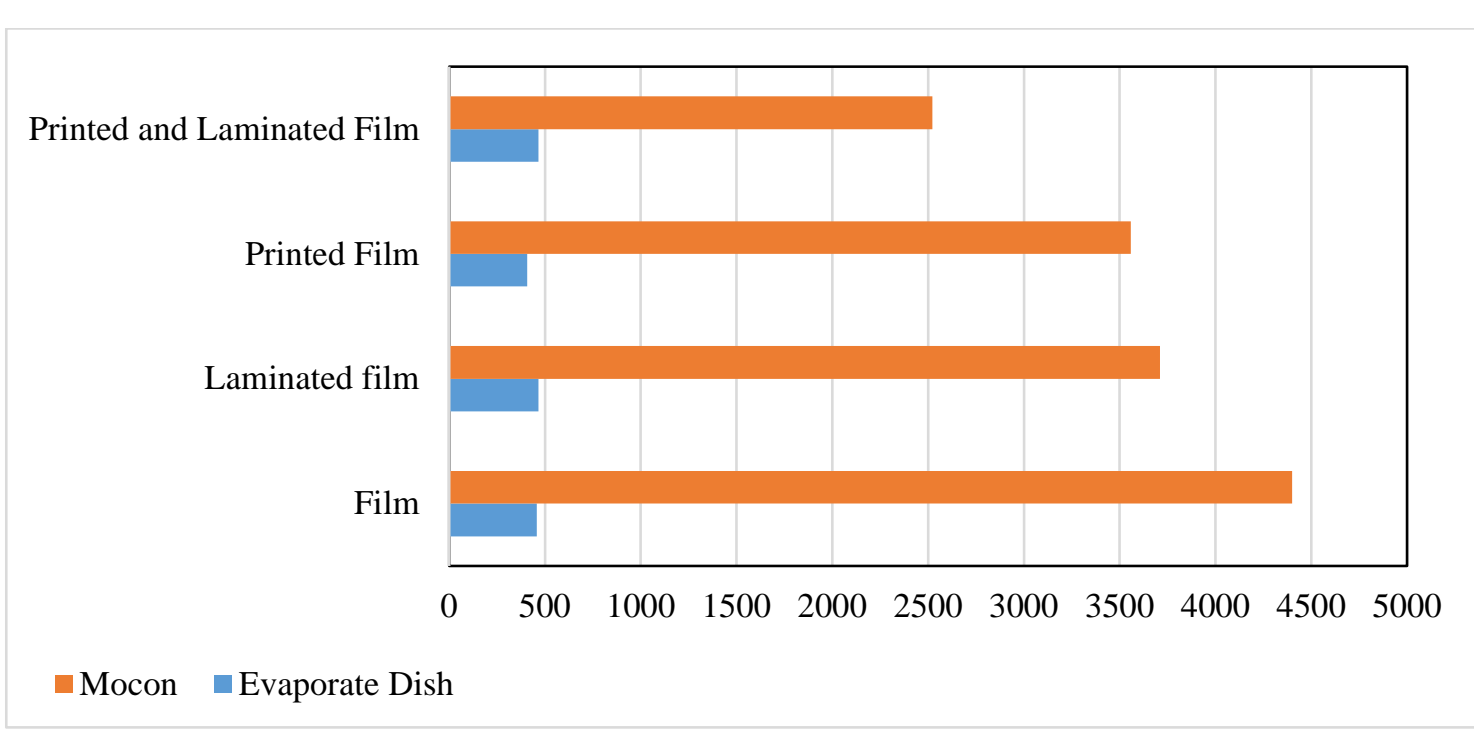

Figure 3. Water vapour permeability test results

As it can be seen from both table 2 and figure 3, the WVP results for two different test principles are considerably different. The situation is a result of ambient conditions that are generated by different test principles. The water vapour transfer through the samples is achieved by water vapour gradient between textile surfaces. If the water vapour pressure that is generated in the microclimate between the textile surface and water vapour source, the water vapour is enforced harder to be transferred through the textile surface. On the other hand, it can be seen from the results that the WWP of samples do not have an important difference for evaporative dish method, whereas there is a significant difference among the 
samples for WVP measured by Mocon test device. Since, Mocon test device ensures higher temperature and humidity during water vapour permeability test. The ambient conditions that the test device performs during the WVP measurement provide a better simulation of real usage conditions. According to WVP results measured by Mocon test device, the highest value is obtained for breathable film material. In comparison to film material, laminated film and printed film samples have lower WVP values. Both lamination and printing processes cause a decrease on WVP. In lamination process film material is laminated with a spun bonded nonwoven fabric layer by using adhesive. So, it is an expected result to have lower WVP value due to providing higher thickness and more amount of material in unit area for the obtained textile surface. On the other hand, printing process decreased the WWP more than lamination process. This is a critical result that even if the printing process does not provide coloration and covering the entire surface by a colorant material, there is an important level of WVP decrease after the process. The situation may be attributed to the pressure that is applied to the entire surface of the film material by rotary screens during printing process. The printing process may negatively affect the pore structure of the film surface. The lowest WVP value is obtained with the printed-laminated sample. Regarding the WVP values of the printed sample and laminated sample, it is an expected result for the printed-laminated sample to have the lowest WVP value. Since, both lamination and printing processes have a decreasing effect on WVP.

ANOVA results for evaporative dish method and Mocon test device are given in table 3 and table 4, respectively.

Table 3. ANOVA results for Evaporative Dish method

\begin{tabular}{|c|c|c|c|c|c|}
\hline Groups & $\begin{array}{c}\text { Sum of } \\
\text { Squares }\end{array}$ & df & $\begin{array}{c}\text { Mean } \\
\text { Square }\end{array}$ & F & Sig. \\
\hline $\begin{array}{c}\text { Between } \\
\text { groups }\end{array}$ & 11831.600 & 3 & 3943.867 & 1.108 & 0.375 \\
\hline Within groups & 56941.600 & 16 & 3558.850 & & \\
\hline Total & 68773.200 & 19 & & & \\
\hline
\end{tabular}

Table 4. ANOVA results for Mocon test device

\begin{tabular}{|c|c|c|c|c|c|}
\hline Groups & Sum of Squares & df & Mean Square & F & Sig. \\
\hline $\begin{array}{c}\text { Between } \\
\text { groups }\end{array}$ & 9025244.950 & 3 & 3008414.983 & 62.716 & 0.000 \\
\hline $\begin{array}{c}\text { Within } \\
\text { groups }\end{array}$ & 767505.800 & 16 & 47969.050 & & \\
\hline Total & 9792749.750 & 19 & & & \\
\hline
\end{tabular}

According to ANOVA results of evaporative dish method, there is no statistically significant difference among WVP values of the samples, whereas there is statistically significant difference among the samples tested by Mocon test device.

\section{CONCLUSION}

Disposable diapers can be divided into two groups as breathable and non-breathable. Today generally breathable disposable diapers are used due to keeping child's skin dry, providing a comfortable feeling to the child and prevent diaper rash. The production of breathable diapers is possible by using the breathable back sheet layer which is the most outer layer of the disposable diaper. The back sheet is composed of spun bonded nonwoven layer and PE film. The laminated layer is then printed for an attractive look. 
This study aims to investigate the effects of laminating and printing processes on baby diaper back sheet material breathability. For this aim, WVP of breathable film material is determined and compared with the products after printing, lamination and printing-lamination. Consequently, it is observed that, the printing and lamination processes have nearly same deterioration effect on the breathability back sheet material. In addition, WVP value is decreased with approximately $45 \%$ as a result of both lamination and printing processes in comparison to film layer. It can be concluded that even if the film material is produced with a high level of breathability, the process parameters of the post processes must be controlled precisely for a good level of end product breathability.

\section{REFERENCES}

[1] Uyanık, S., Kaynak H.K., Non-Breathable Baby Diaper Back Sheet, In: Technical Journal, 2018, 12, 2, 74-78

[2] Dyer, D., Seven decades of disposable diapers. A Record of Continuous Innovation and Expanding Benefit, 2005, Available at: https://www.edana.org/docs/default-source/absorbent-hygieneproducts/edana---seven-decades-of-diapers.pdf?sfvrsn=3e24da15_2 [Accessed on June 2021]

[3] Krafchik, B., History of diapers and diapering, In: International Journal of Dermatology, 2016, $55,11,4-6$

[4] Yaman, N., Senol M.F., Tayyar, A.E., Alternative test methods for assessing mechanical properties of disposable diapers, In: Fibres and Textiles in Eastern Europe, 2007, 15, 2, 80-84

[5] Özen, İ., Çinçik, E., Şimşek, S., Thermal comfort properties of simulated multilayered diaper structures in dry and wet conditions, In: Journal of Industrial Textiles, 2016, 46, 1, 256-278

[6] Gündüz Oktay, E., Research About Influential Factors On Performance Characteristics Of Different Brand Disposable Baby Diapers And Their Comparison, PhD Thesis, Pamukkale University Institute Of Science Textile Engineering, 2018

[7] Akin, F., Spraker, M., Aly, R., Leyden, J., Raynor, W., Landin, W., Effects of Breathable Disposable Diapers: Reduced Prevalence of Candida and Common Diaper Dermatitis, In: Pediatric Dermatology, 2001, 18, 4, 282-290

[8] Yuan, C., Takagi, R., Yao, X.Q., Xu, Y.F., Ishida, K., Toyoshima, H., Comparison of the Effectiveness of New Material Diapers versus Standard Diapers for the Prevention of Diaper Rash in Chinese Babies: A Double-Blinded, Randomized, Controlled, Cross-Over Study, In: BioMed Research International, 2018, 6

[9] Owa, A.B., Oladokun, R.E., Osinusi, K., Diaper dermatitis among children in Ibadan, Nigeria: frequency and predisposing factors, In: Eur. J. Pediat. Dermatol., 2016, 26, 135-141

[10] Srinivas, S.M., Dhar, S., Advances in diaper technology, In: Indian J Paediatr Dermatol, 2016, 17, 83-86

[11] Wright, A., Akin, F., Comfort Perception of Breathable and Nonbreathable Diapers, In: International Nonwovens Journal, 2005, 14, 3, 19-22

[12] Grove, G.L., Lemmen, J.T., Garafalo, M., Akin, F.J., Assessment of Skin Hydration Caused by Diapers and Incontinence Articles, In: Skin Bioengineering Techniques and Applications in Dermatology and Cosmetology, Basel, Karger, 1998, 26, 183-195

[13] TS 12127 Tekstil-Kumaşlar-Küçük numuneler kullanarak birim alan başına kütlenin tayini

[14] TS 7128 EN ISO 5084 Tekstil-Tekstil ve tekstil mamullerinin kalınlık tayini

[15] BS 7209:1990 Specification for water vapour permeable apparel fabrics

[16] ASTM D6701 - 21 Standard Test Method for Determining Water Vapor Transmission Rates Through Nonwoven and Plastic Barriers 